\title{
PERFORMANCE OF WETNESS SENSORS USED IN PLANT DISEASE FORECASTING
}

\author{
W.R. HENSHALL and R.M. BERESFORD \\ The Horticulture and Food Research Institute of New Zealand Ltd., \\ Mount Albert Research Centre, Private Bag 92169, Auckland
}

\begin{abstract}
Flat plate wetness sensors mounted inside apple leaf canopies, and cylindrical sensors mounted outside canopies, indicated shorter wetness durations than flat plate sensors, both exposed and in mesh enclosures, mounted outside canopies. Visible surface wetness on leaves in apple and apricot leaf canopies was most accurately predicted by either flat plate sensors inside the canopy or cylindrical sensors outside the canopy. Top leaf surfaces were wet for longer than bottom leaf surfaces and electronic sensors predicted top surface wetness better than bottom surface wetness. Cylindrical sensors predicted both top and bottom leaf surface wetness better than other types. The electronic sensors all over-predicted actual wetness duration in leaf canopies, and the implications of this for recognizing infection periods of apple black spot and other plant pathogens needs further investigation.
\end{abstract}

Keywords: Leaf wetness sensors, disease forecasting, Venturia inaequalis, apple

\section{INTRODUCTION}

The importance of free water on plant surfaces in the development of disease means that some measure of leaf wetness is often used as an input into models of infection by pathogens. Unfortunately, the duration of leaf wetness is difficult to define because different parts of leaves and canopies wet and dry at different times (Huber and Gillespie 1992). Not surprisingly, wetness sensors placed in different parts of a tree canopy show considerable inter-sensor variation (Penrose and Nicol 1996).

Orchard 2000 decision support software (Laurenson et al. 1994) includes the SpotCheck program for monitoring apple black spot infection periods, based on the duration of surface wetness (Beresford and Spink 1992). Surface wetness in this application is measured by a flat plate electronic sensor, mounted with other weather sensors within orchard shelter but outside the apple canopy to avoid spray deposits. In order to improve the accuracy of black spot infection period recognition, a better understanding of the relationship between the electronic sensor and wetness in leaf canopies is required.

This paper reports a study which compared three designs of electrical impedence wetness sensor, and investigated the relationship between wetness measured electronically and actual wetness in fruit tree leaf canopies. The study also investigated the effects of mesh enclosures around sensors, in an attempt to better simulate the wetting and drying characteristics of leaf canopies.

\section{Sensor comparisons}

\section{MATERIALS AND METHODS}

The wetness sensor used as a standard for comparison was that used on Orchard 2000 weather stations, a flat fibreglass plate (unpainted) with interleaved gold-plated copper strips on the surface (Gillespie and Kidd 1978; Campbell Scientific Instruments, Utah, Model 237). Other types compared were a perspex cylinder with interleaved nichrome wire helices (Young et al. 1979) and a flat fibreglass plate with tinned copper electrodes in the shape of a cereal leaf, developed at Long Ashton Research Station (LARS), U.K. (Huband and Butler 1984).

Proc. 50th N.Z. Plant Protection Conf. 1997: 107-111 
Sensors were mounted $1.5 \mathrm{~m}$ above ground and were inclined $10^{\circ}$ to the horizontal, facing North. They were attached to a mast within the meteorological enclosure at the HortResearch Mt Albert Research Centre (March and May 1995) or adjacent to an experimental block of apple trees at the Mt. Albert site (October 1996).

The effects of enclosing the standard sensor in mesh cages in an attempt to better simulate the leaf canopy microclimate were studied for three separate periods:

a) March 1995: Standard sensors were mounted in the centres of cube-shaped enclosures of three sizes, small $(120 \mathrm{~mm})$, medium $(180 \mathrm{~mm})$ and large $(240 \mathrm{~mm})$ made from $4 \mathrm{~mm}$ expanded aluminium mesh. Also compared were the cylindrical and LARS sensors.

b) May 1995: Standard sensors were mounted in three $120 \mathrm{~mm}$ cube-shaped enclosures: 1) expanded aluminium, as before; 2 ) expanded aluminium mounted on a wooden frame; 3) $1.5 \mathrm{~mm}$ plastic mesh mounted on a wooden frame. These were also compared with the cylindrical and LARS sensors.

c) October 1996: A standard sensor was mounted under a stack of three plastic meshes ( $2 \mathrm{~mm}$ mesh size) at the bottom of a cylindrical plastic tube $(190 \mathrm{~mm}$ dia. $\mathrm{x} 150 \mathrm{~mm}$ high) which was open at the top and bottom. This aimed to restrict air movement around the sensor while not completely preventing rainfall or dew deposition. This was also compared with cylindrical sensors on the mast and with standard sensors mounted on a branch $1.5 \mathrm{~m}$ above ground in the canopy of a cv. Royal Gala apple tree, $20 \mathrm{~m}$ north of the mast sensors.

All sensors were wired to a Campbell CR10 data logger in an a.c. bridge configuration and outputs were scaled from $0-100$, where 0 was the driest and 100 the wettest reading. Sensors were scanned every minute and mean readings were logged every 15 minutes when at least one sensor exceeded $5 \%$ wetness, or hourly when all sensors were below $5 \%$. Most comparisons used averaged data from two replicate sensors.

Wet period start times were identified when output from any sensor in a comparison went above $50 \%$ wetness and finish times were identified when the last sensor fell below $50 \%$. Some wet periods were continuous, with a well defined beginning and end, whereas others were interrupted by short dry intervals within a particular wet weather situation. Fifteen minute output periods when the mean sensor reading was above $50 \%$ were included in the summation of wetness for each sensor.

\section{Leaf wetness observations}

The actual wetness of leaves in an experimental orchard containing apples and apricots at Mt Albert Research Centre was related to the output from the electronic wetness sensors described above, as follows:

a) March 1995: Eight apple and 14 apricot extension shoots were monitored visually. All leaves on each tagged shoot were observed during drying after daytime rain showers, or morning dew, at 1-2 hour intervals. Leaves were scored for visible wetness in seven categories: 0) No surface water, 1) up to $5 \%$ of total leaf surface wet, 2) 5-25\% wet, 3) $25-50 \%$ wet. 4) 50-75\% wet, 5) 75-100\% wet, 6) all leaves $100 \%$ wet. Upper and lower leaf surfaces were recorded separately. Average percentage wetness at each time of observation was derived using the mid-value of each category.

b) October 1996: Twenty extension shoots on five apple trees (2 cv. Gravenstein, $1 \mathrm{cv}$. Royal Gala, 2 cv. Granny Smith) were tagged and observed as above. Most observations were made at night during dew formation, although some were made during the day after rain or dew wetness.

\section{Sensor comparisons}

\section{RESULTS AND DISCUSSION}

Relative wetness durations for each sensor tested in the three study periods are shown in Fig. 1. A relative duration near 1.0 indicates that the test sensor was similar to the standard sensor and a narrow range between the $25 \%$ and $75 \%$ quartiles indicates that discrepancies between the test and standard sensors were consistent. Durations of individual wet periods ranged from 0.25 to 108 hours, with a mean of 14 hours.

The cylindrical sensors indicated shorter wetness durations than the standard 


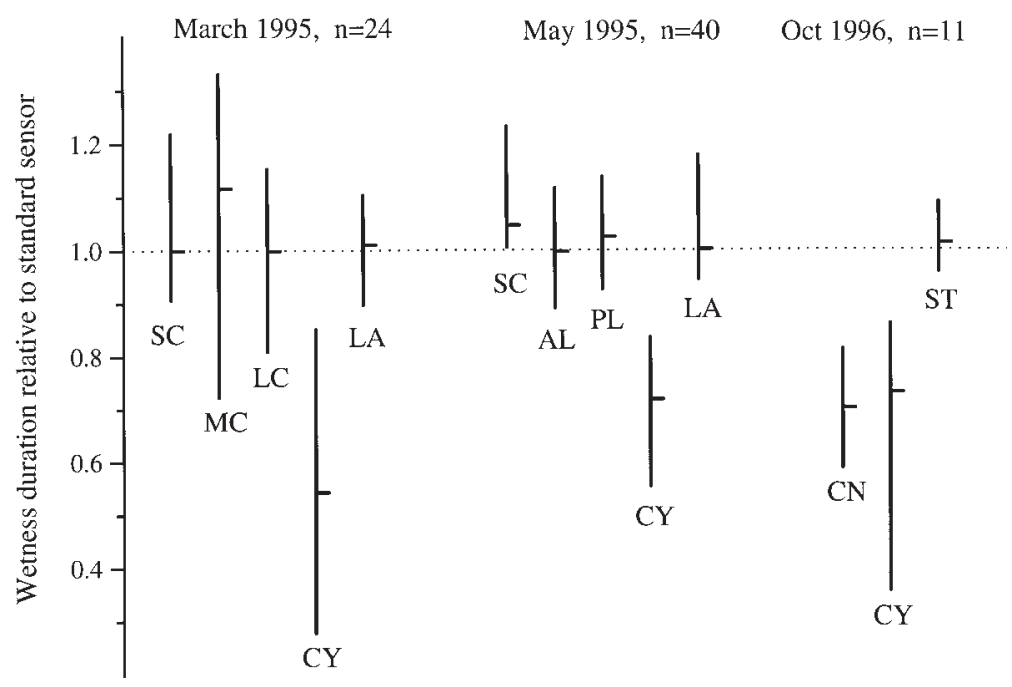

FIGURE 1: Relative duration of wetness for each sensor type/enclosure, as the median ratio and $25 \%-75 \%$ quartiles of ratios for each sensor to the standard mast sensor. $\mathrm{SC}, \mathrm{MC}, \mathrm{LC}=$ small, medium and large cubes; $\mathrm{CY}=$ cylindrical; $\mathbf{L A}=\mathbf{L}$ ong Ashton; $\mathbf{A L}$ and $\mathbf{P L}=$ aluminium and plastic cubes on wooden frames; $\mathrm{CN}=$ leaf canopy; $\mathrm{ST}=$ plastic mesh stack.

sensors, while the LARS sensor was similar to the standard. The various enclosures around the standard sensor had little effect on recorded wetness duration. Flat plate sensors mounted in the canopy recorded shorter wetness durations than than those mounted outside the canopy and were more similar to the cylindrical sensors.

Relationship of sensors to observed leaf wetness

Correlations between observed percentage wetness and percentage wetness from electronic sensor output over the previous 15 minutes were all significant for the March 1995 observations, although correlation coefficients were generally low (Table 1). The cylindrical sensors gave the highest correlations for both top and bottom leaf surfaces. March 1995 observations were mostly made during drying after daytime rain. Correlations for bottom surfaces tended to be lower than for top surfaces because rain often did not wet the bottom surfaces of leaves.

The October 1996 observations (Table 1), were mostly during night dew formation and the sensors in the apple leaf canopy and the cylindrical sensors on the mast gave the highest correlations. The standard sensor mounted on the mast gave a significant but low correlation coefficient for top leaf surfaces. The lack of a significant correlation for bottom surfaces arose because the standard sensor predicted wetness when there was none, probably because the standard mast sensor could radiate directly to the sky, allowing dew to form much earlier than occurred on lower leaf surfaces.

Simple correlation of observed wetness duration with sensor output over the previous 15 minutes tended to give a pessimistic view of the degree of association between predicted and observed wetness, because, although the percentage values did not match well, both often tracked in a similar manner over time with one lagging behind the other in a variable way.

\section{TABLE 1: Correlation coefficients between observed percentage leaf wetness}


and sensor output.

\begin{tabular}{clcc}
\hline Date $^{1}$ & Sensor & Top surface & Bottom surface \\
\hline March 1995 & Standard & $.49 * * *$ & $.39 * *$ \\
& Small cube & $.52 * * *$ & $.40 * *$ \\
& Medium cube & $.48 * * *$ & $.35 *$ \\
& Large cube & $.55 * * *$ & $.41 * *$ \\
& Cylindrical & $.77 * * *$ & $.76 * * *$ \\
October 1996 & LARS & $.62 * * *$ & $.50 * * *$ \\
& Standard & $.32 *$ & $.22 \mathrm{~ns}$ \\
& Std, in canopy & $.82 * * *$ & $.60 * * *$ \\
& Cylindrical & $.79 * * *$ & $.64 * * *$ \\
& Mesh Stack & $.28 \mathrm{~ns}$ & $.23 \mathrm{~ns}$ \\
\hline
\end{tabular}

$\mathrm{ns}=$ not significant $(P>0.05) ; *=P<0.05 ; * *=P<0.01 ; * * *=P<0.001$

${ }^{1}$ March 1995 results based on 52 observations, Oct 1996, 41 observations

In practical use, in the Orchard 2000 Spot Check program, electronic sensor output is interpreted as being either wet or dry, using a 50\% threshold. In keeping with this, tables were made for mean observed leaf wetness when sensor output over the previous 15 minutes was either greater or less than $50 \%$ (Table 2). For top leaf surfaces, "dry" sensors were associated with observed leaf wetness well below 50\%. However, "wet" sensors were also associated with observed leaf wetness below 50\%, except for the cylindrical sensors in 1995. For bottom leaf surfaces, "dry" sensors were associated with almost completely dry leaves and "wet" sensors were also associated with observed leaf wetness below $50 \%$ in all cases.

In 1995 the cylindrical sensor gave the best prediction of wetness on top surfaces of leaves, and in 1996 the in-canopy sensors and cylindrical sensors were similarly the best. Prediction of wetness on bottom leaf surfaces was worse than on top surfaces. The poor associations between wet and dry categories for sensors and leaf observations were all due to over-prediction of wetness by the sensors, particularly for bottom leaf surfaces. Factors likely to have influenced the accuracy of prediction include leaf canopy density affecting the local microclimate, and whether leaf wetness originated from rain or from dew.

TABLE 2: Mean observed wetness on top and bottom leaf surfaces when sensor outputs over the previous 15 minutes were either dry $(<50 \%)$ or wet $(>\mathbf{5 0 \%})$.

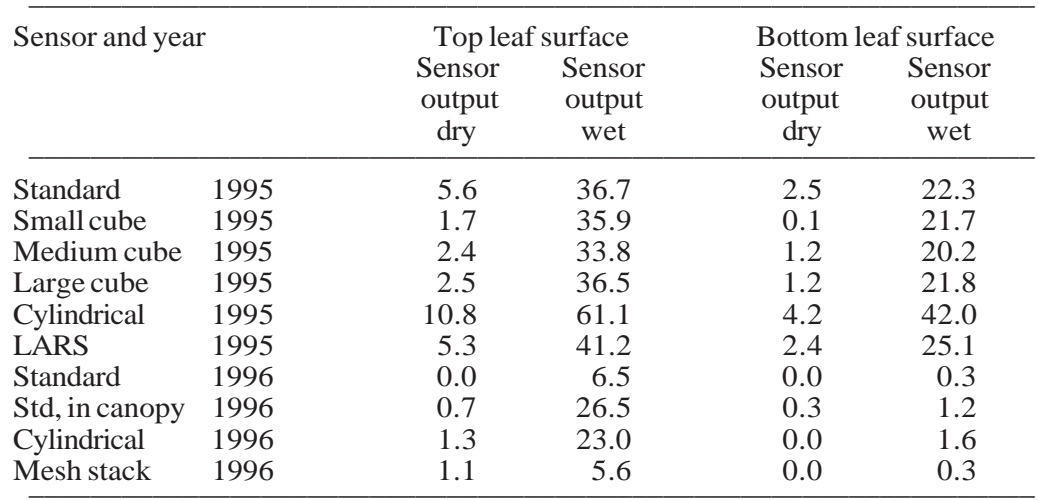


All wetness sensors examined represented leaf canopy leaf wetness reasonably well, although most sensors under most conditions over-predicted canopy wetness. Therefore, the standard mast mounted wetness sensors used on Orchard 2000 weather stations are likely to give a conservative estimate of wetness duration for disease prediction purposes. This conclusion requires further study because it contradicts casual observations from orchardists involved with apple black spot infection period monitoring who have sometimes suggested that apple leaf canopies might stay wet longer than electronic wetness sensors indicate.

There were large differences between top and bottom leaf surfaces in their wetting and drying characteristics. The cylindrical sensors tended to represent both top and bottom surfaces better than did flat plate sensors alone or in enclosures. Although the standard flat plate sensor inside a tree canopy was as good as the cylindrical sensor, this deployment option is not considered practical because agrichemical deposits from pesticide spraying alter the performance of sensors and must be avoided.

Greater accuracy of wetness monitoring might be gained by further development of the cylindrical type of sensor. The surface of the cylindrical sensor can exchange radiation with both the sky and the ground, whereas the flat plate sensor radiates to the sky only. Therefore, the wetting and drying characteristics of the cylindrical sensor are probably more similar to a leaf canopy than are those of a flat plate sensor, either within or outside the canopy.

\section{ACKNOWLEDGEMENTS}

The authors thank Mike Spink for designing sensor enclosures, John-Pieter Schipper, Roel Veenstra and Paul Rose for leaf canopy observations and the Foundation for Research, Science and Technology for funding this research.

\section{REFERENCES}

Beresford, R.M. and Spink, M., 1992. A national disease forecasting system for apple black spot (Venturia inaequalis) in New Zealand. Acta Hort. 313: 285-296.

Gillespie, T.J. and Kidd, G.E., 1978. Sensing duration of leaf moisture retention using electrical impedence grids. Can. J. Plant Sci. 58: 179-187.

Huband, N.D.S. and Butler, D.R., 1984. A comparison of wetness sensors for use with computer or microprocessor systems designed for disease forecasting.British Crop Prot. Conf. 2: 633-640.

Huber, L. and Gillespie, T.J., 1992. Modelling leaf wetness in relation to plant disease epidemiology. Annu. Rev. Phytopathol. 30: 553-577.

Laurenson, M.R., Buwalda, J.G. and Walker, J.T.S., 1994. Orchard 2000 - a decision support system for New Zealand's orchard industries. N.Z. J. Crop Hort. Sci. 22: 239-250.

Penrose, L.J. and Nicol, H.I., 1996. Aspects of microclimate variation within apple tree canopies and between sites in relation to potential Venturia inaequalis infection. N.Z. J. Crop Hort. Sci. 24: 259-266.

Young, K., Galbreath, N.H. and Hewett, E.W., 1979. A system of regulating sprinkling during evaporative cooling of apple buds to delay bloom.J.Agric. Eng. Res. 24:20913. 